\title{
VISUAL POSITION AND JUXTAPOSITION: AN ANALYTICAL STUDY OF LIBERTY LEADING THE PEOPLE AND MOON-WOMAN CUTS THE CIRCLE
}

\author{
Yashoda Chaulagain*
}

\section{ABSTRACT}

This paper explores the idea of romantic and modern painting with the reference of Delacroix's painting "Liberty Leading the People" and Jackson Pollock's painting "Moon Woman Cuts the Circle". Both painters representing different era, portray different styles, background, color, tempo, and textures in their painting. Delacroix's painting expresses inner emotions and realistic world. His painting is emotional, it seems to be natural and exotic. He has used arches, sculptures, and gray color dominantly. In contrast to Delacroix, Pollock's painting is experimental. It has abstraction and two-dimensionality. It looks rational that represents the frustrated and chaotic world in abstract form. In this sense, Delacroix's painting "Liberty Leading the People" represents the liberty, equality, and fraternity. A woman personifying the concept and the goddess of liberty leads the people forward over the bodies of the fallen men holding the flag of the French Revolution. On the other hand, Jackson Pollock's painting "Moon Woman Cuts the Circle" reflects the modern world representing woman the symbol of peace, color tempo suggests the domination of violence and bloodshed. The weapon shows the domination of the power which is violent. Delacroix's painting suggests the hope of change and bright future but Pollock seems to be pessimistic in his painting.

Keywords: Romantic painting, modern painting, abstract form, natural, impressionist, visual texture, landscape.

\section{INTRODUCTION}

Ferdinand Victor Eugene Delacroix is a French painter of romantic period. Most of his paintings are oil on canvas made in romantic style. Romantic painting has different features than that of Renaissance and Neoclassical painting. It is also different from modern painting in its structures and themes. Romantic painting is characterized by emotionalism and fascination with the exotic. The emphasis on personal feeling and emotion,

* Ms. Chaulagain is a Lecturer, Siddhartha Vanasthali Science Campus, TU. 
celebration of intuition, spontaneity, individualism, and revolutionary energy are seen especially in the painting of romanticism. Most of the paintings are inspired by the dreams. The feelings of nationalisms are prominent of many artists. We can see in Delacroix's painting too (Fig.1). In contrast to Romantic paintings, modern paintings are radical. Modern Art departs from earlier traditions because it redefines the convention of painting. Previous arts are religious and allegorical in nature but modern arts are fractured and abstract in nature (Fig.2). Romantic painting shows the figure and theme clearly, it is as same as real events. But in modern painting, figures are juxtaposed and showed the theme of uncertainty because modern paintings are the creation of unconscious mind.

\section{ANALYSIS}

Delacroix's painting Liberty Leading the People was produced in 1830 and subject of this work is derived from the world famous French Revolution. On the other hand, Jackson Pollock's painting Moon Woman Cuts the Circle was produced in 1943 which shows the passionate intensity of the painter. He pursued his personal vision through painting. Pollock is known as the abstract painter which is the modern trend of painting reflecting the reality in the mysterious and complex way. Whereas Delacroix is very romantic in his approach towards choosing the subjects of his painting as he always looks upon mythology, history and literature. Delacroix's painting gives the clear picture of the war, where one half naked woman is leading people. We can easily judge the intensity of the painter. But if we look the modern painting we do not find the meaning and the intention of painter in visible form rather it is found in round about way. Pollock's painting Moon Woman Cuts the Circle is also abstract expressionist painting. We see contrasting elements, and different patches in the surface therefore it is too difficult to find out the figure in the painting.

Jackson Pollock, the modern abstract expressionist painter, primarily concerned with the spontaneous assertions of the individual through the act of painting. His paintings are difficult to interpret by using our common sense because its figure and background, its images and situation, colors and shapes are presented in difficult way. In this sense, Clement Greenberg says, "The splash application of paint equal by crowding the picture plane into a compact jumble- a jumble that is another vision" (767). According to Greenberg, the abstract paintings are crowded compact jumble and 
juxtaposed. It is the symbols of irrationality and anxiety of the modern people. Modern abstract paintings are invisible in relation to romantic or the painting of other era. Romantic painting like (Fig.1) is visible and can understand the meaning as well as recognize the picture clearly. Therefore, we can analyze the painting very easily. The use of colors, shape, size, texture, structure and images are clear to understand. Most of the paintings are seen that there is mingled of art and nature. What Friedrich Wilhelm von Schelling argues, "Nature and art is the link that connects idea and form, body and soul [...] stands an eternal idea, formed in the infinite understanding" (459). He views that nature and art are interrelated interconnected as body and soul. Such combination of body and soul is found in Delacroix's painting because his painting shows the form (body) clearly, which leads the viewer to dig out the substance of the painting.

Delacroix's shape of painting can be divided into triangles and rectangles which are balanced geometrical shapes. The painting is balanced due to the fact that the middle figures along with three other marching figures representing uprising which makes a triangular composition. The canvas is divided into two horizontal rectangles consisting of lying dead bodies and active human beings respectively. In contrast to Romantic paintings of Delacroix, the modern paintings of Pollock are bizarre and strange. He begins to design mural size, drip paintings which he becomes famous for. He drips and throws the paint using hand and wrist gestures. Pollock fixes canvas to the floor and drips paint from a canvas using variety of objects to manipulate the paint. He also inclines to use more industrials tools such as trowels, knives, and sticks to apply paint to canvas. His painting seems to be flat where he pours the color unconsciously so we feel difficult to understand his painting. Clement Greenberg in his essay, "Modernist Painting" talks about the flat shapes of the modern painting. He admits, "The making of pictures, as against images in the flat, means the deliberate choice and creation of limits. This deliberateness is what modernism harps: [. . . it spells out the fact that limiting conditions of art have to be made ..." (759). He asserts modern art in terms of shape and images. Modern art is the production of unconscious mind. Most of the painters pour the color in the palate unconsciously so, the image cannot be made in flat. They use brush deliberately that is why picture occurs in abstract form. 
Colors play dominant role in abstract painting. The complex painting by Pollock Moon-Woman Cuts the Circle has painted in mess and grotesque. The background of the painting is completely blue and the images are complex as well as mysterious. The background blue is dominated by red colors which symbolically suggest the idea of modern world to be pictured. It is the suggestion of over shadow of peace but the domination of violence and bloodshed which are the common features of the modern world. The use of colors in Pollock's painting symbolizes the loss, anxiety, fear, and violence of the modern fragmented people. Greenberg further explicates, "Spread over an absolutely, not merely relatively, large areas. [. . .] suggest indeterminate space: more blue simply being bluer than less blue. This too is why the picture has to be confined to do so few colors [...] the vision of the two-three color pictures" (768). Greenberg's view indicates the modern paintings are dominated by the primary colors that are blue, red and yellow. It means modern people seek calm and peaceful life. The domination of blue color with two or three colors suggests the indeterminate space in the painting. By using primary color, Pollock also tries to show the reality of the American society. On the other hand, the Romantic paintings are different in using color. To show the picture naturally, Romantic painter use gray color dominantly in their painting which shows prosperity and hope of the people.

Romantic painter, Delacroix uses colors to show atmospheric or aerial perspective. He uses atmospheric perspective with the hazy sky and the buildings in the city using a very cool color. It is different from Pollock's style of coloring. Delacroix uses many different tints, adding white to a hue, and shades, adding black to a hue, of brown, red, blue, and black. His use of brown color is a dark brown, which is on the low part of the scale shows the power of the people. The lightest areas are around the lady 'Liberty' and the dark areas are around the outside of 'Liberty' shows the focal point of the work is done by her.'Liberty' stands out more than the other figures because she is carrying the flag with bright colors of red, blue and white. His brush strokes are bolder, more confident and vigorous. His colors are cleaner and brighter, compositions are more direct and simpler. His use of colors show that he is moving towards the impressionist painting which is an ingredient feature of modernism. What LionelloVenturi states, "[. . . the many colors found in the reflexes suggested to them the idea of expressing light by opposing colors without using dark tones for shadow" (35). His 
view shows that impressionist uses the light color instead of dark for the shadow in the painting. Delacroix's painting also shows same thing, he has used light color for shadow.

Delacroix's painting is predominated by cold colors. His use of color is striking. The use of color for the contrast and shading of lights carry the features of modern art. His style of painting symbolizes his journey begins from romanticism continues till impressionism. To prove this view Paul Signac articulates, "The descending lines, cold colors and dark tones predominate; a more or less perfect balance of warm and cold colors, of pale and intense tones is added to the calm of the horizontal lines" (22). Signac talks about the color combination of Delacroix's painting. For him the use of cold colors, pale tones and balance of warm color give the life to Delacroix's painting. By using such type of color combination he tries to show the warm nature of 'Liberty' in the painting.

Moreover, Delacroix loves to use texture in his work. Visual texture an illusion something appears to the actual texture. The two sides are not a mirror image of each other but the both symmetrical balance, and a symmetrical balance possess about the same visual weight. In contrast to Delacroix, Pollock's use of texture is some strange and odd. The use of color makes difficult to the viewer how it is recognized, his presentation of woman figure with crown and knife shows there is not any balance in the palate. The painting is unconventionally presenting the woman as a destructive factor. In talking about texture Pollock says in his interview, "I have no fears about making changes, destroying the image, etc. because the painting has a life of its own. [. . . . It is only when I lose contact with the painting that the result is a mess otherwise there is pure harmony. $[\ldots]$ The method of painting is the natural growth out of a need. I want to express my feelings rather than illustrate them" (576). His imagination is supposed to show his intention of making his painting different. He has not attention and concentration in painting rather he further admits, "painting is the natural growth out of a need" (576). His painting is only expression of his personal feelings making the viewer difficult to understand.

Jackson Pollock focuses on the unconscious expression of human feelings in his painting. He elaborates, "The unconscious is a very important side of modern art and I think the unconscious drives to mean a lot in looking at painting" (575). The unconscious is a perception rather than an actuality, 
and that the unconscious is also a model that is structuralized by society and is administered by the production of self-identity and conformation with in society. To reveal the reality of modern world, painter should be unconscious. So, most of the modern art is made unconsciously as a result it is made abstract. The creation of abstract art is necessary in modern period in order to show the depression, chaos, and disorder of the people in the society.

M. H. Abrams in his A Glossary of Literary Terms writes, "The expressionist artist undertakes to express a personal vision- usually a troubled or tensely emotional vision of human life and human society" (62). Abrams statement is similar to Pollock's representation of human life in his paintings which he was sketching in the palette. Therefore, he shows the fragmented life of modern people which he has experienced in his life. He presents woman, who is responsible to destroy the boundary of the society in his painting. His painting (Fig. 2) presents the woman like figure with knife cutting the circle of the tradition in modern world.

Pollock's use of color lines in painting shows the disinterested, despair life of the modern people. He has used black, brown, and gray lines in the painting, which shows the violence and despair along with the breaking of the man- woman circle of harmony and creative regeneration. Supporting this claim Charles Van Doren argues, "The vast Pollock, in intricate web of black, brown and gray lines and white ground, is cool, calm, and cerebral" (362). Van Doren asserts that Pollock's painting (Fig.2) is the web of black, brown, and gray lines with white ground, which signify the calm, purity, revolution as well as hopeless life of modern people. But the romantic painter, Delacroix's linings are different in painting. Liberty Leading the People, which leads towards peace and prosperous life after completion of revolution. Most of the figures are outlines with black color. Some are little thicker than other. 'Liberty' is looking at the man who has worn the top hat. The man holding himself up is looking at liberty. Delacroix lines are quick, fluid and imprecise. Furry of curve liner shows the web and knot. The use of medium of lining allows for blending and the shading. No hatching is used his use of colors and lines make easy to understand the theme of the painting.

However, the image in the picture of romantic painting, (Fig.1), is suggestive and symbolic. There are four different types of images: the 
images of the environment, human images, the weapons and the darkness. Delacroix represents female character as a symbolic personification of national independence. His vision of liberty appropriates the feminine image to connect together the two worlds: a mythical world and popular realistic world. His references symbolize the antique divinities. They are motivated by his romantic spirit and certainly not by the modern concept of the 'Gaze'. This image may be a brilliant allegory of freedom to many. It also shows the female figure representing the struggle for the uprising. Her bare foot and carelessly exposed breast indicates that she is life giving mother, who has really concerned about the well being of the people and to eliminate their misery and death. She also looks heroic figure. The weapons in the hands of liberty and young boy symbolize that they have just got victory over the tyrant king in France. The weapons are means of seizing power. Explaining this argument,Van Doren asserts, "Power is in the muzzle of the gun" (230). Power is always within the gun. It comes from the muzzle of the gun. Moreover, the gun holding in left hand by 'Liberty' symbolizes that she has got victory by using gun. Similarly, dead bodies signify the war victims who are innocent people. The lack of unity and hesitation of bourgeoisie's position is illustrated by the man with the top hat. He gives an impression of moving but the position of the rifle in his hands suggest uncertainty. The woman as an allegorical liberty represents the principle structure of social health to any nation. The woman's healthy naked torso and her basic dress refer to the popular identity of the nation's real root.

To talk about the image of modern painting, it's too difficult to find out picture in the palette. We cannot find the image due to the abstract and fractured nature of the painting. Pollock's painting also complex and juxtaposed to find the real picture. It is absurd in the sense that chaotic and disjoined patterns play important role in his painting. The dominant blue color in background and red, yellow and white colors suggest purity, revolution, uncertainty and calm. Half circle of the moon is painted on the top of the painting. There are many dots and spots in the surface of the moon. There are more unidentified images covering the whole space of painting.

On the basis of an astronomy, it can be interpreted that painting is related to the relation between moon and ocean. The moon is directly affected if there are high tides on the ocean. These high tides caused a lot of spots on the surface of the moon which are called creates. To support 
this view, Roy Boyne explains, "Often expressed potential for harmony between man, woman, and nature, which contrasted with the disharmonious social picture which emerges from many pictures" (62). Boyne's optimistic view suggests that modern people should have harmony with nature. It is similar to Pollock's painting. His painting (fig.2) might be trying to show the harmony among the man, woman and the nature. The modern people are destroying nature due to the separation of culture from nature. So, by presenting, man figure, woman figure, and river at the same palette, he may be convincing the modern people that man is not a conqueror but a member of biotic community where each and every member has equal right to live and blossom.

In contrast to Pollock, Delacroix's painting is allegorical in nature. The liberty woman or freedom fighter is allegorical figure. The woman's bare foot standing on the solid ground emphasizes the allegorical and sculptural representation of Greek Goddess of 'victory'. His 'Liberty' represents the artist's homage to many women fighting besides the men during the 'July' revolt. Her dress refers to the "'Peplos' according to Victor Hugo, which Greek women wear and its yellow symbolizes the power of divine energy, light, stability, sublime purity of judgment, spiritual maturity and prosperity" (16). The man, who is standing left side of liberty both the waving pistols, symbolizes the new generation, which is revolting against the ruling dispotic regime, authoritarian and hungry for social change. In this sense, Pollock's painting has also some images; such as moon- woman, boats, ship, river, male picture and knife. The moon image, the weapons, as well as mysterious female figure in the painting suggest the attempt of the painter to reflect the cultural festivals of the Americans. Similarly, we can analyze that the woman with knife shows the moon woman is cutting the traditional circle of the society. She wants freedom, flying in the open sky; the family life is no more existing. It is shown through the fracture of the relationship between husband and wife. And feminine figure seems to be destroying the existing social norms.

\section{CONCLUSION}

Both painters try to show the reality of the society but they represent the same thing in different way. Delacroix, the Romantic painter presents the historical things very clearly. On the other hand, Jackson Pollock, the modern painter expresses his mental feeling and societal feeling in abstract 
form. Delacroix presents female figure as 'Liberty' who leads people towards fraternity, and brotherhood. She is represented protective figure, hope of life, who looks for bright future. She looks as if she is only possibility of human life. She can pave the way to the people. She is a figure who wants to introduce change in the society. Pollock's representation of woman is different than of Delacroix. He may not have hope that female can save the society from the fraction. When we see in the painting, the style, shape, and texture denote that painting itself shows the abstract life of the people. His representation of the woman in painting shows women in the world are in favor of change in the society. Therefore, 'Moon- Woman,' crazy woman cuts the traditional boundary. These both painters presented the theme of 'change' in their paintings. Delacroix's painting represents the female figure as a life giving breast- feeding mother who opposes the destruction of oppression and war. Pollock's moon woman depicts the state of the manwoman relationship as well as that of the family and culture deviated by divorce and loss of the values in the west. This mind disturbing picture is like the life and love of many people in the western world. Delacroix has a hope of bright future whereas Pollock's painting shows that the painter is pessimistic.

In nutshell, Eugene Delacroix's painting Liberty Leading the People represents the theme of nationalism through female figure 'Liberty'. He has used symbolism and mythical allegory in his painting. On the other hand, modern painting, Moon-woman cuts the Circle by Jackson Pollock, who is the abstract expressionist, represents the theme of uncertainty, fragmentation, disharmony and chaos of modern life. By looking these two paintings we can say that the modern paintings are totally deviated from romantic or traditional painting. It carries new techniques to express the disinterestedness, irrationality, violence and loss of human values in modern life. 
200 VISUAL POSITION AND JUXTAPOSITION: AN ANALYTICAL ...

\section{Appendix}

Fig. 1: Liberty Leading the People by Eugene Delacroix.

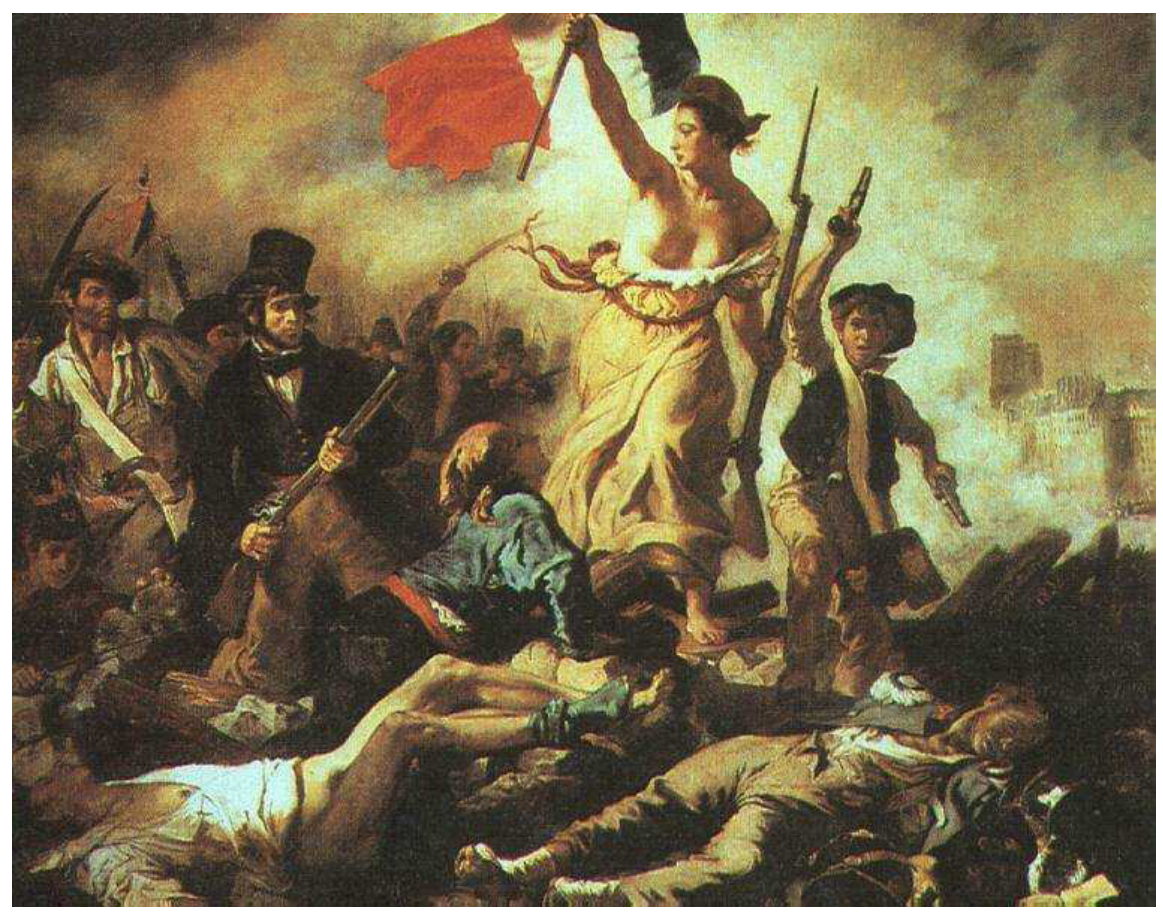


Fig. 2: Moon Woman Cuts the Circle by Jackson Pollock.

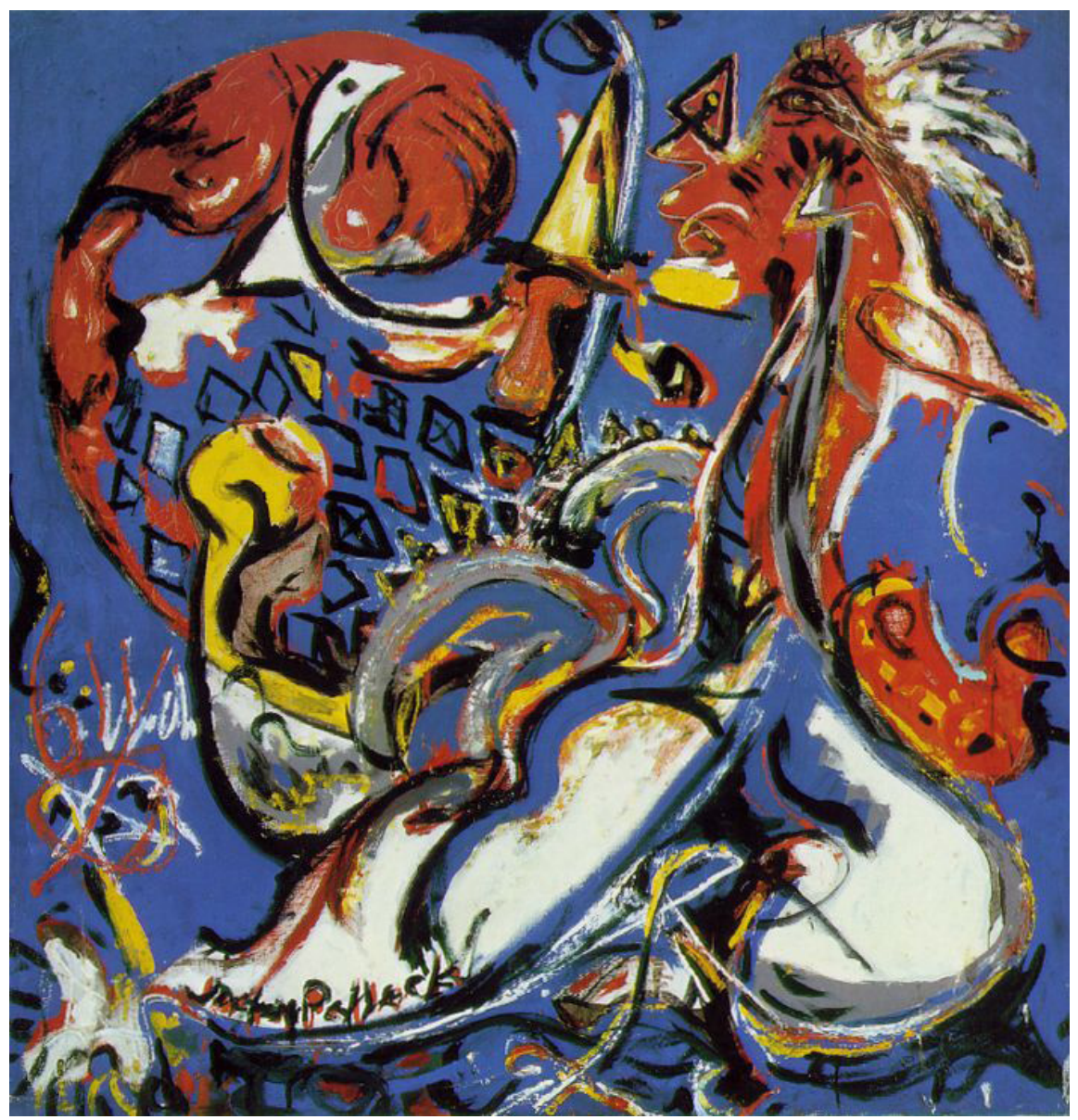




\section{WORKS CITED}

Abrams, M. H. A Glossary of Literary Terms, USA: Cornel UP, 1993.

Boyne, Roy. "Fractured Subjectivities." Visual Culture. Ed. Chris Jenks. USA: Routledge, 2006, pp. 42- 46.

Delacroix, Eugene. "Liberty Leading the People." Critical and Creative Thinking. Eds. Shreedhar Lohani and et. al. Kathmandu: Educational Enterprise, 2000, p.192.

Greenberg, Clement."Modernist Painting." Art in Theory. Eds. Charles Harrison and Paul Wood. UK: Blackwell, 1999, pp.754-760.

Hugo, Victor "Delacroix, Eugene". Journal 1822-1863. Paris: Editions Plon, 1996, http://pijet.com/2009/03/21/delacroixs-painting-libertyleading-the-people/\#_ftn16.

Pollock, Jackson. "An Interview with William Wright." Art in Theory. Eds Charles Harrison and Paul Wood. UK: Blackwell, 1999, pp.574578.

Pollock, Jackson. "Moon Woman Cuts the Circle." Critical and Creative Thinking. Eds. Shreedhar Lohani and et. al. Kathmandu: Educational Enterprise, 2000. p. 196.

Signac, Paul. "From Eugene Delacroix to Neo-Impressionism." Art in Theory. Eds. Charles Harrison and Paul Wood. UK: Blackwell, 1999, pp.20-23.

Van Doren, Charles. A History of Knowledge: Past, Present and Future. New York: Ballantine Books, 1992.

Venturi, Lionello. "The Aesthetic Idea of Impressionism." The Journal of Aesthetics and Art Criticism. 1.1, 1941, pp. 34-45. 